\title{
Don't burn the baby: Advice from Australian nurses recommending therapeutic sun exposure during infancy
}

\author{
Simone Lee Harrison", Jane Nikles, Madeleine Nowak \\ JCU Skin Cancer Research Group, Anton Breinl Centre, School of Public Health, Tropical Medicine and Rehabilitation Sciences, \\ James Cook University, Townsville, Australia; ${ }^{*}$ Corresponding Author: simone.harrison@jcu.edu.au \\ Received 10 January 2013; revised 8 March 2013; accepted 10 April 2013 \\ Copyright (C) 2013 Simone Lee Harrison et al. This is an open access article distributed under the Creative Commons Attribution \\ License, which permits unrestricted use, distribution, and reproduction in any medium, provided the original work is properly cited.
}

\section{ABSTRACT}

Background: Previous studies have demonstrated inappropriate advice from health professionals advocating therapeutic sun exposure during infancy and the post-partum period. This study examines the proportion of Australian midwives and related hospital nursing staff who recommend therapeutic sun exposure during this period. Methods: Questionnaires were completed by 363 Australian nurses (57.2\% response) responsible for nursing post-partum women in $\mathbf{1 1}$ maternity hospitals in Queensland (QLD) and the Australian Capital Territory (ACT). Results: Many nurses believed sun exposure was beneficial in treating: cracked nipples (QLD $41.3 \%$, ACT 65.8\%; $p<0.001$ ), neonatal jaundice (QLD 49.6\%, ACT 75.3\%; $p<0.001$ ), nappy rash (QLD 23.2\%, ACT $30.3 \% ; p=0.207$ ) and acne (QLD $12.3 \%$, ACT $16.9 \%$; $p=0.291$ ) and made recommendations consistent with their beliefs. Relatively few nurses stipulated sunning through glass or specified exposure time limits. Nursing staff from public hospitals in QLD, but not the $A C T$, were more likely than nurses from private hospitals to hold one or more such beliefs ( $p=$ 0.008 ). Approximately $40 \%$ of respondents thought people generally looked healthier with a suntan; $79 \%$ of this group also held one or more risky beliefs about therapeutic sun exposure $(p=0.043)$. Conclusion: A high proportion of these nurses held risky beliefs about the beneficial uses of sunlight for post-partum women and their infants and made recommendations consistent with their beliefs. Professional education is needed to change the beliefs and practices of nursing staff about intentional sun exposure of women and their babies to reduce their longterm skin cancer risk, particularly as Australia has such a high prevalence of skin cancer.

Keywords: Therapeutic Sun Exposure; Nursing Staff; Midwives; Beliefs; Practices; Skin Cancer Prevention

\section{INTRODUCTION}

The commonest malignancy in Australia is nonmelanocytic skin cancer [1], which costs the Australian health system around \$264 million per year, considerably more than any other form of cancer [1]. Within Australia, Queensland has the highest incidence of non-melanocytic skin cancer [1,2] and a very high incidence of melanoma [1]. Queensland children have numerous melanocytic naevi (MN) [3], the strongest known risk factor for melanoma [4]. The development of both melanoma and $\mathrm{MN}$ is related to early childhood sun exposure [3,5, 6]. Early protection against sunlight is important for prevention of melanoma as lifetime risk is associated with childhood sun exposure [7]. However, previous research has shown that some Queensland mothers intentionally expose their infants to sunlight for perceived health- related reasons [8].

The use of sunlight for medicinal purposes dates back to ancient Rome and Greece [9] and current practices relevant to infancy still appear to include using sunlight to: treat mild neonatal jaundice; alleviate nappy rash; prevent rickets; and ensure adequate Vitamin D production [8].

A study of 114 post-partum women in north Queensland found that $8 \%$ of their Caucasian term infants had received phototherapy, while $12.5 \%$ had been exposed to sunlight by their mothers to treat mild/suspected neonatal 
jaundice [8]; this unnecessary sun exposure may lead to future skin neoplasia. Forty percent of multiparous women had intentionally exposed at least one of their children to sunlight for suspected neonatal jaundice. Over half those who had sunned a baby for jaundice used direct sunlight with many exposing their baby naked for up to 30 minutes at a time. Only $18.8 \%$ sunned their infant through a window (glass filters most ultraviolet radiation-B from sunlight [10]) [8].

Twenty percent of these women living in tropical Australia believed they should intentionally expose their baby to sunlight to prevent vitamin D deficiency, while $10.5 \%$ believed sunlight was a good treatment for nappy rash [8]. In most cases, advice to mothers to sun their baby had been given by a heath professional (midwife/nurse 41\%; doctor/paediatrician 28\%) [8]. Similar studies in Canberra $\left(35.3^{\circ} \mathrm{S}\right)$ and Brisbane $\left(27.5^{\circ} \mathrm{S}\right)$ found risky beliefs about therapeutic sun exposure during infancy were widespread among post-partum women, with $62 \%$ having at least one such inappropriate belief [11]. Participants in all three cities reported they would intentionally expose their baby to sunlight if a health professional advised them to do so.

The present study was conducted to examine the beliefs of Australian midwives and related hospital nursing staff about therapeutic sun exposure and determine the proportion recommending these practices during infancy and the post-partum period.

\section{METHODS}

A 4-page cross-sectional self-administered postal survey of hospital-based nursing staff responsible for the care of post-partum women and neonates was undertaken to determine beliefs and practices about therapeutic sun exposure. The questionnaire has been described previously [12].

\subsection{Subjects}

Participants were 635 midwives, registered nurses and enrolled nurses who regularly worked in obstetric and post-natal wards of one of three hospitals in the Australian Capital Territory (ACT) or one of eight hospitals in Queensland (QLD). The survey was conducted in the ACT in August 1998 in all local maternity hospitals operational at that time and in QLD between March 1999 and April 2000 in the largest maternity hospitals (based on number of deliveries performed in 1996) in Cairns, Townsville, Mackay, Rockhampton, the Gold Coast, and Brisbane. Reminder letters were sent to non-respondents from QLD (but not the earlier ACT study). 3 - 4 weeks after the initial questionnaire.

Ethics approval was obtained from each participating hospital.

\subsection{Statistical Methods}

Mean values and 95\% confidence intervals (95\%-CI) are presented for normally distributed numerical values and median values together with inter-quartile ranges (IQR) if the distribution is skewed. Bivariate analyses comparing those who agreed with the therapeutic use of sunlight, against those who disagreed or were unsure were performed using Wilcoxon rank sum tests (WRS) for continuous variables and Chi-square tests $\left(\chi^{2}\right)$, Fisher's Exact test (FE) or $\chi^{2}$ for trend being used as appropriate for categorical variables. Statistical analysis was performed using SPSS for Windows version 20. A p-value of 0.05 was regarded as statistically significant.

\section{RESULTS}

\subsection{Participants}

The response rate for QLD $(59 \% ; \mathrm{n}=286)$ was higher than for the ACT $(51.3 \% ; \mathrm{n}=77)$, with similar response rates for north QLD [56.1\%; $\mathrm{n}=96]$, central QLD $[60.5 \%, \mathrm{n}=49]$ and southern QLD [59.7\%, $\mathrm{n}=141])$. The average age of QLD participants was 40 years [95\%-CI: 38.9 - 41.1], range 21 - 66 years. No age data were obtained for ACT participants. The majority of participants were midwives, worked in the public sector and had trained in Australia (Table 1).

\subsection{Beliefs about Therapeutic Benefits of Sun Exposure}

More than half the nursing staff (55.1\%) considered "it is acceptable to intentionally expose Australian infants to sunlight to treat neonatal jaundice" while almost half $(46.5 \%)$ believed "sunlight is a good remedy for cracked nipples". These beliefs were more prevalent among nursing staff in the ACT than in QLD $(\mathrm{p}<0.001$; Table 2).

More nurses from QLD (68\%) than the ACT (88.3\%) held at least one risky belief about sunlight therapy $(\mathrm{p}<$ 0.001 ), with a latitude gradient (ACT, which is temperate, 88.3\%; subtropical QLD 72.3\% [south of Rockhampton]; tropical QLD 64.1\% [Rockhampton and north]: p < 0.001). In QLD, nurses working in public hospitals were significantly more likely than nurses from private hospitals to have risky beliefs about therapeutic sun ex- posure $(70.3 \%$ versus $43.5 \% ; \mathrm{p}=0.008)$. This trend was not evident in the ACT (85\% versus $91.1 \% ; p=0.347)$. Age and years since qualifying (available for QLD only: $\mathrm{p}=$ 0.131 and 0.289 , respectively) were not significant predictors of risky beliefs. These beliefs were relatively equally distributed between midwives, other nursing staff and ancillary nursing staff (e.g. enrolled nurses) in QLD $(\mathrm{p}=0.606)$, and between midwives and other nursing staff in the ACT ( $p=0.52$; no ancillary nursing staff surveyed). 
Table 1. Demographic characteristics of midwives and other nursing staff working in hospital maternity wards in Queensland and the Australian Capital Territory (ACT).

\begin{tabular}{|c|c|c|c|c|}
\hline & $\begin{array}{c}\text { Total } \\
(\mathrm{n}=363)\end{array}$ & $\begin{array}{l}\text { Queensland } \\
(\mathrm{n}=286)\end{array}$ & $\begin{array}{c}\text { A.C.T } \\
(n=77)\end{array}$ & p-value ${ }^{\#}$ \\
\hline \multicolumn{5}{|l|}{ Occupation } \\
\hline Midwife & $84.6 \%(307)$ & $81.5 \%(233)$ & $96.1 \%(74)$ & \multirow{4}{*}{$\mathrm{FE} \mathrm{p}=0.005^{\ddagger}$} \\
\hline Registered Nurse (RN) & $9.1 \%(33)$ & $11.2 \%(32)$ & $1.3 \%(1)$ & \\
\hline Enrolled Nurse (EN) & $2.8 \%(10)$ & $3.5 \%(10)$ & $0.0 \%(0)$ & \\
\hline Other $^{\dagger}$ & $3.6 \%(13)$ & $3.8 \%(11)$ & $2.6 \%(2)$ & \\
\hline \multicolumn{5}{|l|}{ Employer } \\
\hline Public & $83.5 \%(303)$ & $92.0 \%(263)$ & $51.9 \%(40)$ & \multirow[t]{2}{*}{$\chi^{2} \mathrm{p}<0.001$} \\
\hline Private & $16.5 \%(60)$ & $8.0 \%(23)$ & $48.1 \%(37)$ & \\
\hline \multicolumn{5}{|l|}{ Place trained } \\
\hline Australia & $86.7 \%(314)$ & $87.4 \%(249)$ & $84.4 \%(65)$ & \multirow{4}{*}{ FE $p=0.625$} \\
\hline UK, USA, Ireland or Europe & $10.2 \%(37)$ & $9.8 \%(28)$ & $11.7 \%(9)$ & \\
\hline New Zealand & $1.7 \%(6)$ & $1.8 \%(5)$ & $1.3 \%(1)$ & \\
\hline Other ${ }^{*}$ & $1.4 \%(5)$ & $1.1 \%(3)$ & $2.6 \%(2)$ & \\
\hline \multicolumn{5}{|l|}{ Time since completion of nursing training ${ }^{+}$} \\
\hline$<10$ years & & $40.0 \%(114)$ & - & \\
\hline $11-20$ years & & $32.3 \%(92)$ & - & \\
\hline $21-30$ years & & $18.6 \%(53)$ & - & \\
\hline$>30$ years & & $9.1 \%(26)$ & - & \\
\hline \multicolumn{5}{|l|}{ Birthplace } \\
\hline Australia & $77.1 \%(279)$ & $75.8 \%(216)$ & $81.8 \%(63)$ & \multirow{4}{*}{$\chi^{2 \mathrm{t}} \mathrm{p}=0.214$} \\
\hline UK & $8.6 \%(31)$ & $8.4 \%(24)$ & $9.1 \%(7)$ & \\
\hline New Zealand & $4.4 \%(16)$ & $5.3 \%(15)$ & $1.3 \%(1)$ & \\
\hline Other & $9.9 \%(36)$ & $10.5 \%(30)$ & $7.8 \%(6)$ & \\
\hline \multicolumn{5}{|l|}{ Place of birth for Australian born nurses } \\
\hline Born in Queensland & $45.2 \%(126)$ & $54.6 \%(118)$ & $12.7 \%(8)$ & \multirow{7}{*}{ FE: $\mathrm{p}<0.001^{\ddagger}$} \\
\hline Born in NSW or ACT & $31.5 \%(88)$ & $23.6 \%(51)$ & $58.1 \%(37)$ & \\
\hline Born in Victoria & $15.1 \%(42)$ & $14.4 \%(31)$ & $17.5 \%(11)$ & \\
\hline Born in South Australia & $3.9 \%(11)$ & $3.7 \%(8)$ & $4.8 \%(3)$ & \\
\hline Born in Western Australia & $1.7 \%(5)$ & $1.9 \%(4)$ & $1.6 \%(1)$ & \\
\hline Born in Tasmania & $1.8 \%(6)$ & $1.9 \%(4)$ & $3.2 \%(2)$ & \\
\hline Born in Northern Territory & $0.4 \%(1)$ & $0.0 \%(0)$ & $1.6 \%(1)$ & \\
\hline \multicolumn{5}{|l|}{ Where lived most of life } \\
\hline Australia & $90.1 \%(327)$ & $90.9 \%(260)$ & $87.0 \%(67)$ & \\
\hline \multicolumn{5}{|l|}{ If Australia: } \\
\hline QLD & $58.4 \%(191)$ & $72.7 \%(189)$ & $3.0 \%(2)$ & \multirow{7}{*}{ FE: $\mathrm{p}<0.001^{\ddagger}$} \\
\hline NSW/ACT & $28.2 \%(92)$ & $15.4 \%(40)$ & $77.6 \%(52)$ & \\
\hline VIC & $8.3 \%(27)$ & $8.1 \%(21)$ & $9.0 \%(6)$ & \\
\hline SA & $2.4 \%(8)$ & $1.9 \%(5)$ & $4.5 \%(3)$ & \\
\hline WA & $1.5 \%(5)$ & $1.2 \%(3)$ & $3.0 \%(2)$ & \\
\hline Tas & $0.9 \%(3)$ & $0.8 \%(2)$ & $1.5 \%(1)$ & \\
\hline NT & $0.3 \%(1)$ & $0.0 \%(0)$ & $1.5 \%(1)$ & \\
\hline Time spent in the local area (median [IQR]yrs) & $14[5,27]$ & $13[5,26]$ & $15[7.9,27.5]$ & MW: $p=0.49$ \\
\hline
\end{tabular}

${ }^{\dagger}$ Other occupations included Student Midwife; Maternity Nurse; Neonatal Nurse; Assistant in Nursing (AIN). * Other includes overseas (country not specified); South Africa; Chile. " p-value refers to comparisons between QLD and ACT. FE = Fisher's Exact test; $\chi^{2}=$ Chi-square test; $\chi^{2 \mathrm{t}}=\mathrm{Chi}$-square test for trend; MW $=$ Mann-Whitney U test. ${ }^{+}$range 0 (one student) to 40 years, median 13 years [IQR 7, 21]; - Data not collected; IQR = Interquartile range. NSW = New South Wales; ACT = Australian Capital Territory; UK = United Kingdom; ${ }^{+}$statistically significant difference.

The proportion of staff with risky beliefs was similar whether they were born in Australia or abroad (QLD p = 0.369 , ACT $\mathrm{p}=0.754$ ) and did not vary according to state of birth $(p=0.555$; Table 3$)$. While there was no significant difference between staff trained in Australia and those trained abroad (QLD p $=0.568$, ACT $\mathrm{p}=$ 0.426 ), the prevalence of risky beliefs was higher for those trained in the ACT, than for those trained in Queensland, South Australia, New South Wales, or Victoria $(p=$
0.021; Table 3).

\subsection{Beliefs about Aesthetic Benefits of Sun Exposure}

Approximately 40 percent of participants thought people generally looked healthier with a suntan, and a similar proportion preferred themselves with a tan (Table 2). Seventy-nine percent $[95 \%$-CI: $74.4 \%-82.8 \%]$ of re- 
Table 2. Beliefs of nurses about the perceived therapeutic and aesthetic benefits of sun exposure.

\begin{tabular}{|c|c|c|c|c|c|c|c|c|c|}
\hline \multirow[b]{2}{*}{ Therapeutic uses of sunlight } & \multirow[b]{2}{*}{$\mathbf{n}$} & \multicolumn{3}{|c|}{ Nurses from Queensland } & \multicolumn{5}{|c|}{ Nurses from the Australian Capital Territory } \\
\hline & & Agree & Disagree & Unsure & $\mathbf{n}$ & Agree & Disagree & Unsure & p-value ${ }^{*}$ \\
\hline Treat neonatal jaundice & 286 & $49.6 \%$ & $43.3 \%$ & $7.0 \%$ & 77 & $75.3 \%$ & $19.5 \%$ & $5.2 \%$ & $<0.001$ \\
\hline To treat nappy rash & 284 & $23.2 \%$ & $72.9 \%$ & $3.9 \%$ & 76 & $30.3 \%$ & $60.5 \%$ & $9.2 \%$ & 0.207 \\
\hline Treat acne & 285 & $12.3 \%$ & $59.6 \%$ & $28.1 \%$ & 77 & $16.9 \%$ & $54.5 \%$ & $28.6 \%$ & 0.291 \\
\hline $\begin{array}{l}\text { For adequate Vitamin D } \\
\text { production in Australian } \\
\text { children }\end{array}$ & 286 & $2.4 \%$ & $94.4 \%$ & $3.1 \%$ & 77 & $6.5 \%$ & $92.2 \%$ & $1.3 \%$ & 0.141 \\
\hline To develop a protective tan & 280 & $1.1 \%$ & $96.8 \%$ & $2.1 \%$ & 76 & $2.6 \%$ & $96.1 \%$ & $1.3 \%$ & 0.290 \\
\hline $\begin{array}{l}\text { People generally look } \\
\text { healthier with a suntan }\end{array}$ & 285 & $40.4 \%$ & $55.8 \%$ & $3.9 \%$ & 76 & $39.5 \%$ & $55.3 \%$ & $5.3 \%$ & 0.890 \\
\hline I think I look better with a tan & 285 & $38.6 \%$ & $57.2 \%$ & $4.2 \%$ & 76 & $39.5 \%$ & $59.2 \%$ & $1.3 \%$ & 0.889 \\
\hline
\end{tabular}

* p-values compare proportion of nursing professionals between states who hold these beliefs (Chi-square test or Fisher's Exact test as appropriate).

Table 3. Differences in the prevalence of risky beliefs about therapeutic sun exposure according to birthplace and state/territory in which nursing training was undertaken.

\begin{tabular}{|c|c|c|c|c|}
\hline & $\begin{array}{l}\text { No. born } \\
\text { in this } \\
\text { state }\end{array}$ & $\begin{array}{l}\text { Proportion of nurses with one or } \\
\text { more risky beliefs about therapeutic } \\
\text { sun exposure by BIRTH PLACE }\end{array}$ & $\begin{array}{l}\text { No. } \\
\text { trained in } \\
\text { this state }\end{array}$ & $\begin{array}{l}\text { Proportion of nurses with one or more } \\
\text { risky beliefs about therapeutic sun } \\
\text { exposure if TRAINED in this state }\end{array}$ \\
\hline Australian Capital Territory & 6 & $83.3 \%$ & 31 & $96.8 \%$ \\
\hline New South Wales & 81 & $79.0 \%$ & 60 & $66.7 \%$ \\
\hline Northern Territory & 1 & $100.0 \%$ & 2 & $100.0 \%$ \\
\hline Queensland & 126 & $67.5 \%$ & 178 & $69.1 \%$ \\
\hline South Australia & 11 & $81.8 \%$ & 7 & $57.1 \%$ \\
\hline Tasmania & 5 & $80.0 \%$ & 5 & $80 \%$ \\
\hline Victoria & 42 & $64.3 \%$ & 20 & $70.0 \%$ \\
\hline Western Australia & 6 & $66.7 \%$ & 9 & $77.8 \%$ \\
\hline Outside Australia & 83 & $74.7 \%$ & 48 & $75.0 \%$ \\
\hline
\end{tabular}

State of birth missing for 1 Australian born respondent.

spondents who believed people generally looked healthier with a suntan also had at least one risky belief about therapeutic sun exposure $(\mathrm{p}=0.043)$.

\subsection{Professional Advice about Sore or Cracked Nipples Associated with Breast Feeding}

The majority of nurses (QLD 88.1\%, ACT 93.4\%) reported they advised women about the treatment of sore or cracked nipples associated with breast feeding during their routine professional duties, with most (QLD 86.8\%, ACT $63.8 \%$ ) providing advice consistent with recom- mendations of the Australian Breastfeeding Association (ABA) [13]. However, a proportion recommended exposing nipples to sunlight (QLD 9.1\%, ACT 27.5\%). There is no reference to sunlight in ABA's current recommendations and this practice is no longer condoned (ABA pers. comm.).

Only $19.5 \%$ of nursing staff advocating this practice mentioned indirect sunlight, with a similar proportion stipulating maximum exposure times. Nurses living in sub-tropical Queensland were significantly more likely than those from tropical Queensland to recommend sunlight $(p=0.002)$ while more recent training was a borderline significant risk factor for QLD nurses $(\mathrm{p}=$ 
0.058; Table 4). The prevalence of these recommendations was highest in the ACT $(27.5 \%)$, followed by sub-tropical Queensland (14.2\%) and lowest in tropical Queensland (3.1\%).

\subsection{Professional Advice about Nappy Rash}

Many respondents advocated using sunlight to treat nappy rash (QLD 23.3\%, ACT 30.3\%). Only 8 of these mention filtered or indirect sunlight or specified an exposure time limit which ranged from explicit directives such as "5 minutes early morning exposure" or "10 minutes per day through a window" to non-explicit statements such as "for a short period" or "for a limited time".

Nurses living in sub-tropical QLD were more likely than nurses from tropical QLD to recommend using sunlight for nappy rash ( $p<0.001$; Table 4$)$. The practice was equally prevalent among staff in ACT (30.3\%) and sub-tropical QLD (32.9\%), but considerably less so among staff from tropical QLD (14\%).

\subsection{Professional Advice about Suspected Neonatal Jaundice}

Many participants reported they would recommend exposing infants to sunlight for suspected neonatal jaundice (QLD 41.9\%, ACT 75\%). Some indicated they suggested exposure either through a window (QLD 20.5\%, ACT 38.6\%) and/or indirect or filtered sunlight (QLD $47 \%$, ACT 15.8\%). However, relatively few specified a maximum exposure period (QLD 20.5\%, ACT 29.8\%); recommendations in QLD ranged from "brief exposure" to 30 minutes and in the ACT from a few minutes to 40 minutes per day. The average exposure period suggested through a window was 8.3 minutes in the ACT and 7.5 minutes in QLD. Where exposure through glass was not stipulated, the average exposure period suggested was 16 minutes in the ACT and 8.6 minutes in QLD. The prevalence of these recommendations was highest in the ACT (75\%), followed by tropical QLD $(45.8 \%)$ and subtropical QLD (38.2\%).

Table 4. Predictors of inappropriate professional advice about therapeutic sun exposure.

\begin{tabular}{|c|c|c|c|c|c|c|}
\hline \multirow[b]{2}{*}{ Recommends using sunlight to: } & \multicolumn{3}{|c|}{ Nurses from Queensland } & \multicolumn{3}{|c|}{ Nurses from the Australian Capital Territory } \\
\hline & $\begin{array}{c}\text { Yes } \\
\text { (median or \%) }\end{array}$ & $\begin{array}{c}\text { No } \\
(\text { median or \%) }\end{array}$ & p-value & $\begin{array}{c}\text { Yes } \\
\text { (median or \%) }\end{array}$ & $\begin{array}{c}\text { No } \\
\text { (median or \%) }\end{array}$ & p-value \\
\hline \multicolumn{7}{|l|}{ Treat cracked nipples? } \\
\hline Age $^{*}$ & 45 years & 38 years & 0.108 & - & - & - \\
\hline Time since completion of training ${ }^{*}$ & 18 years & 12 years & 0.058 & - & - & - \\
\hline Trained in Australia ${ }^{\#}$ & $95.5 \%$ & $88.2 \%$ & 0.303 & $89.5 \%$ & $86.3 \%$ & 0.722 \\
\hline Working in a public hospital ${ }^{\#}$ & $95.5 \%$ & $90.8 \%$ & 0.464 & $47.4 \%$ & $52.9 \%$ & 0.678 \\
\hline Sub-tropical residence ${ }^{\#}$ & $81.0 \%$ & $45.0 \%$ & 0.002 & N/A & N/A & N/A \\
\hline \multicolumn{7}{|l|}{ Treat neonatal jaundice? } \\
\hline Age $^{*}$ & 38 years & 40 years & 0.408 & - & - & - \\
\hline Time since completion of training ${ }^{*}$ & 13 years & 12 years & 0.436 & - & - & - \\
\hline Trained in Australia ${ }^{\#}$ & $85.5 \%$ & $88.3 \%$ & 0.491 & $84.2 \%$ & $84.2 \%$ & 1.00 \\
\hline Working in a public hospital ${ }^{\#}$ & $92.3 \%$ & $92.0 \%$ & 0.919 & $49.1 \%$ & $57.9 \%$ & 0.508 \\
\hline Sub-tropical residence ${ }^{\#}$ & $44.4 \%$ & $52.2 \%$ & 0.203 & N/A & N/A & N/A \\
\hline \multicolumn{7}{|l|}{ Treat nappy rash? } \\
\hline Age $^{*}$ & 42.5 years & 38 years & 0.224 & - & - & - \\
\hline Time since completion of training ${ }^{*}$ & 12.5 years & 13 years & 0.910 & - & - & - \\
\hline Trained in Australia ${ }^{\#}$ & $93.9 \%$ & $85.3 \%$ & 0.070 & $91.3 \%$ & $81.1 \%$ & 0.264 \\
\hline Sub-tropical residence $\mathrm{e}^{\#}$ & $69.2 \%$ & $43.3 \%$ & $<0.001$ & N/A & N/A & N/A \\
\hline
\end{tabular}

"Wilcoxon Rank Sum Test performed; ${ }^{*}$ Chi-squared Test or Fisher's Exact Test performed as appropriate; - Data not collected; N/A Not Applicable. 


\section{DISCUSSION}

Both QLD and the ACT have high levels of ultraviolet radiation (UVR) particularly in summer (average maximum daily UV index is 11 in ACT and 13 in Townsville [14]). Both also have a substantial incidence of melanoma (QLD 81.5/100,000 in males, 54.2/100,000 in females [15] [2005 figures]; ACT 44.6/100,000 in males; $36.8 / 100,000$ in females [2006 figures [16]).

These nursing professionals had a high prevalence of beliefs that may result in them encouraging post-partum women to intentionally expose themselves and their infants to sunlight. These beliefs are similar to those identified previously for post-partum women from QLD [8] indicating that the staff hold similar beliefs to their patients.

The major differences between beliefs of health professionals and those of post-partum women related to exposing Australian children to sunlight to avoid the development of rickets. Only a small proportion of nursing staff ( $3 \%$ ) compared to $20 \%$ of post-partum women from Townsville [8] and $23 \%$ of post-partum women from Brisbane [11] believed it was necessary to intentionally expose Caucasian Australian infants to sunlight to ensure adequate vitamin D levels. Although there is growing concern about vitamin D deficiency in Australians, ambulatory Caucasian adults living in tropical Australia generally have adequate vitamin D levels [17] and deficiency is rarely a problem for Caucasian children raised in Australia [18].

While we found no evidence to support the use of sunlight to treat nappy rash or neonatal jaundice, a significant proportion of nurses advocated this practice. Given the repercussions of excessive sun exposure in early childhood and the effect advocating sun exposure for treatment of neonatal jaundice has on beliefs and behavior of post-partum women, it is inappropriate to recommend using direct sunlight to treat neonatal jaundice, particularly in environments with high UVR [8]. Yet, many nurses in this study reported they would recommend sun exposure for suspected neonatal jaundice. Relatively few stipulated sunning through a windowpane to filter out UVR. Some nurses recommended "indirect" or "filtered" sunlight. However, such inexplicit instructions may be misinterpreted by parents and result in infants receiving considerable doses of reflected UVR under the shade of a tree, particularly as most did not include specific instructions about frequency, duration or appropriate times of day. Like their patients $[8,11]$, nurses who believed sunlight was an appropriate treatment for neonatal jaundice also tended to believe in sunlight therapy for cracked nipples and nappy rash.

\section{Limitations}

While data were collected from the largest maternity hospitals in Queensland and all hospitals in the ACT at the time of the study, the results cannot be extrapolated to other Australian hospitals without further investigation. Working in the public sector appeared to be a significant predictor of holding one or more risky beliefs about therapeutic sun exposure. However this must be interpreted with caution as private nursing staff were underrepresented in Queensland. A more extensive survey in private hospitals in Queensland may be necessary.

\section{CONCLUSION}

As the post-partum period involves frequent contact with nursing professionals, it is important that advice given is safe, consistent and explicit. This study provides evidence that risky beliefs and recommendations about therapeutic benefits of sun exposure in infancy and the post-partum period are common among Australian nurses. This is of particular concern in a country with such a high skin cancer burden. Professional education is needed to change these beliefs. Studies in other locations would be beneficial to determine the extent of these beliefs and practices among health professionals. Furthermore a repeat survey would be useful to compare current beliefs and practices with this study.

\section{ACKNOWLEDGEMENTS}

We would like to thank Lesley Hutton for assisting with coordination of the project, and the management and nursing staff of participating maternity hospitals. This research was funded by a cancer prevention research grant from Queensland Health and salary support for Dr. Harrison was provided by Queensland Health and the Parkes Bequest to James Cook University.

\section{REFERENCES}

[1] Australian Institute of Health \& Welfare (AIHW) (2005) Health system expenditures on cancer and other neoplasms in Australia, 2000-01. AIHW, Canberra.

[2] Büttner, P.G. and Raasch, B.A. (1998) Incidence rates of skin cancer in Townsville, Australia. International Journal of Cancer, 78, 587-593. Erratum in International Journal of Cancer, 2001, 93, 302-303. doi:10.1002/(SICI)1097-0215(19981123)78:5<587::AIDIJC10>3.0.CO;2-E

[3] Harrison, S.L., MacLennan, R., Speare, R. and Wronski, I. (1994) Sun exposure and melanocytic naevi in young Australian children. Lancet, 344, 1529-1532. doi:10.1016/S0140-6736(94)90348-4

[4] Armstrong, B.K. and English, D.R. (1992) Epidemiologic studies. In: Balch, C.M., Houghton, A.N., Milton, G.W., Sober, A.J. and Soong, S.-J., Eds., Cutaneous Melanoma: Clinical Management and Treatment Results Worldwide, 2nd Edition, JB Lippincott, Philadelphia, 12-26.

[5] Holman, C.D. and Armstrong, B.K. (1984) Cutaneous 
malignant melanoma and indicators of total accumulated exposure to the sun: An analysis separating histogenic types. Journal of the National Cancer Institute, 73, 7582.

[6] Armstrong, B.K., De Klerk, N.H. and Holman, C.D. (1986) Etiology of common acquired nevi: Constitutional variables, sun exposure, and diet. Journal of the National Cancer Institute, 77, 329-335.

[7] Harrison, S.L., MacKie, R.M. and MacLennan, R. (2000) Development of melanocytic nevi in the first 3 years of life. Journal of the National Cancer Institute, 92, 14361438. doi:10.1093/jnci/92.17.1436

[8] Harrison, S.L., Buettner, P.G. and MacLennan, R. (1999) Why do mothers still sun their infants? Journal of Paediatrics and Child Health, 35, 296-299. doi:10.1046/j.1440-1754.1999.00362.x

[9] Emmett, A. (1988) The Bare Facts: The effect of sun on skin. Williams \& Wilkins \& Associates Pty Ltd., Sydney.

[10] De Gruijl, F.R. (1997) Artificial light sources and skin cancer: Definition of a carcinogenic action spectrum. In: Altmeyer, P., Hoffmann, K. and Stucker, M., Eds., Skin cancer and UV Radiation, Springer-Verlag, Berlin, Heidelberg, 611-620. doi:10.1007/978-3-642-60771-4_75

[11] Harrison, S., Büttner, P. and Nowak, M. (2005) Maternal beliefs about the reputed therapeutic uses of sun exposure in infancy and the post-partum period. Australian Journal of Midwifery, 18, 22-28. doi:10.1016/S1448-8272(05)80006-9

[12] Harrison, S., Hutton, L. and Nowak, M. (2002) An inves- tigation of professional advice advocating therapeutic sun exposure. Australian and New Zealand Journal of Public Health, 26, 108-115. doi:10.1111/j.1467-842X.2002.tb00901.x

[13] Australian Breastfeeding Association (2011) Sore/cracked nipples. Accessed 16 August 2012.

www.breastfeeding.asn.au/bf-info/common-concerns-mu $\underline{\mathrm{m} / \text { sore-cracked-nipples }}$

[14] Average solar ultraviolet (UV) Index. Average noon clear sky UV index for summer in Australia. Accessed 21 October 2012.

http://www.bom.gov.au/jsp/ncc/climate averages/uv-inde $\mathrm{x} /$ index.jsp?period $=$ sum.

[15] Queensland Cancer Registry (2008) Cancer in Queensland, incidence and mortality, 1982 to 2005. The Cancer Council Queensland, Brisbane.

[16] ACT Cancer Registry (2009) Cancer in the ACT: Incidence and mortality 2002-2006. ACT Health, Canberra.

[17] Nowak, M., Harrison, S.L., Buettner, P.G., et al. (2011) Vitamin D status of adults from tropical Australia determined using two different laboratory assays: Implications for public health messages. Photochemistry and Photobiology, 87, 935-943. doi:10.1111/j.1751-1097.2011.00941.x

[18] Munns, C.F., Simm, P.J., Rodda, C.P., et al. (2012) APSU vitamin D Study Group. Incidence of vitamin D deficiency rickets among Australian children: An Australian Paediatric Surveillance Unit study. Medical Journal of Australia, 196, 466-468. doi:10.5694/mja11.10662 